\title{
BMJ Open Barriers and facilitators associated with steps of the HIV care cascade for migrants in OECD countries: a systematic mixed studies review protocol
}

Anish Arora (D) , ${ }^{1,2,3}$ Amelie Quesnel-Vallee, ${ }^{4,5}$ David Lessard, ${ }^{2,3}$ Kedar Mate, ${ }^{1,2,3}$ Adriana Rodriguez-Cruz,, ${ }^{1,2,3}$ Nadine Kronfli, ${ }^{2,6}$ Kim Engler, $^{2,3}$ Isabelle Vedel (D) ,' Bertrand Lebouché, ${ }^{1,2,3,6}$ In collaboration with the Antiviral Speed Access Program (ASAP) Migrant Advisory Committee

To cite: Arora A, QuesnelVallee A, Lessard D, et al. Barriers and facilitators associated with steps of the HIV care cascade for migrants in OECD countries: a systematic mixed studies review protocol. BMJ Open 2020;10:e040646. doi:10.1136/ bmjopen-2020-040646

- Prepublication history and additional material for this paper are available online. To view these files, please visit the journal online (http://dx.doi. org/10.1136/bmjopen-2020040646).

Received 18 May 2020 Revised 03 September 2020 Accepted 23 October 2020

Check for updates

(C) Author(s) (or their employer(s)) 2020. Re-use permitted under CC BY-NC. No commercial re-use. See rights and permissions. Published by BMJ.

For numbered affiliations see end of article.

Correspondence to

Mr Anish Arora;

anish.arora@mail.mcgill.ca

\section{ABSTRACT}

Introduction In 2019, the United Nations signalled a substantial rise in the number of international migrants, up to 272 million globally, about half of which move to only 10 countries, including 8 member nations of the Organization for Economic Co-operation and Development (OECD). Migrants in OECD countries are often at higher risk for acquiring HIV and have a higher frequency of delayed HIV diagnosis. The barriers and facilitators that migrant people living with HIV (PLWH) in OECD countries face in relation to HIV care are insufficiently understood. The five-step HIV Care Cascade Continuum (HCCC) is an effective model to identify gaps, barriers and facilitators associated with HIV care. The purpose of this study is to generate a comprehensive, multilevel understanding of barriers and facilitators regarding the five steps of the HCCC model in OECD countries by migration status.

Methods and analysis A systematic mixed studies review using a data-based convergent design will be conducted. Medline, Embase, Scopus, CINAHL and the Cochrane Library will be searched on 25 March 2020. Screening and critical appraisal will be conducted independently by the first author. Authors $3-5$ will act as second reviewers, each independently conducting $33 \%$ of the screening and appraisal. Quantitative data will be transformed to qualitative data and be synthesised using thematic analysis. The Mixed Methods Appraisal Tool will be used for quality assessment. An advisory committee, composed of four migrant PLWH, will be involved in screening and appraising $5 \%$ of articles to build knowledge and experience with systematic reviews. They will also be involved in analysis and dissemination.

Ethics and dissemination Ethics approval was obtained from the McGill University Health Centre (15-188-MUHC, 2016-1697, eReviews 4688). Publications arising from this study will be open-access.

PROSPERO registration number CRD42020172122.

\section{Strengths and limitations of this study}

- This protocol consists of a review methodology that facilitates the synthesis of qualitative, quantitative and mixed-methods studies.

- Centring around the HIV Care Cascade Continuum model, this synthesis will provide a comprehensive and multilevel understanding of barriers and facilitators impacting access to HIV care by people living with HIV with different migratory statuses in Organization for Economic Co-operation and Development countries.

- Patient engagement at each step of the literature review and synthesis is expected to centre the analysis and interpretation of results on patients' concerns, which will be critical to ensuring the relevance of the research to this population and increased knowledge translation and impact.

- Limits include risks of low inter-rater reliability due to the number (4) of reviewers involved in the screening and appraisal of studies.

- Strategies have been implemented to mitigate risk of inconsistencies, including the use of workshops, screening guides, and maintaining communication and regular meetings between reviewers.

\section{INTRODUCTION}

International migrants are people engaging in all forms of movement across countries, temporarily or permanently, and for a variety of reasons. ${ }^{2}$ As of September 2019, the United Nations estimated that there were 272 million international migrants globally, a number that has increased by 51 million since $2010 .^{3}$ Approximately $50 \%$ of all international migrants travel to and reside in only 10 countries, ${ }^{3} 8$ of which are members of the Organization for Economic Co-operation and Development (OECD). ${ }^{4}$ 
An extensive body of literature highlights that several international migrant populations in OECD countries are at increased risk of acquiring HIV infection and are more likely to experience delayed HIV diagnosis and linkage to care compared with native-born populations. ${ }^{5-24}$ The International Organization for Migration, a leading intergovernmental organisation established in 1951, has called for efforts to be made in the reduction of barriers to HIV health services for migrant populations. ${ }^{22}$

An understanding of the barriers and facilitators experienced by various international migrant populations visa-vis HIV care is needed. To support this understanding, the HIV care cascade continuum (HCCC) presents a series of healthcare steps that assist in ensuring optimal health outcomes for people living with HIV (PLWH), as well as in effectively gauging national and international goals associated with HIV such as the 90-90-90 target proposed by the United Nations Programme on HIV/ AIDS. ${ }^{25-27}$ The HCCC model consists of five steps: (1) diagnosis; (2) linkage to care; (3) treatment provision (ie, receiving HIV medical care); (4) retention in care and (5) achievement of viral suppression. ${ }^{26}{ }^{27}$ Engagement and retention in each of these steps is important to achieve and maintain viral suppression, which provides optimal clinical benefit and quality of life for patients, with suppressed risk of HIV transmission to others such as host populations. ${ }^{28}$ Data from some OECD countries indicate that migrant populations have a delayed entry into the HCCC and are at an increased risk for discontinuity in the HCCC compared with host populations. ${ }^{29-31}$ Different barriers and facilitators impact access to and delivery of care at the individual, organisational and policy levels at each step of the HCCC. Thus, this model could be used alongside a social-ecological model to identify barriers and facilitators in a comprehensive manner.

Several systematic reviews have reported barriers and facilitators associated to specific HCCC steps for migrant PLWH in high-income countries. ${ }^{714} 19$ 32-35 These reviews, however, focus on HIV health-seeking behaviour, ${ }^{34}$ on only certain steps of the HCCC, mostly screening, ${ }^{74} 193435$ and on specific migrant populations such as migrants from sub-Saharan Africa and South East Asia, ${ }^{34}$ labour migrants ${ }^{32}$ and displaced populations. ${ }^{33}$ There is a lack of knowledge on barriers and facilitators with respect to all steps of the HCCC and other migrant populations, such as non-status or undocumented immigrants, refugee claimants and asylum seekers, transient migrants (ie, visitors or tourists) and international students living with HIV. Additionally, though migrant populations are very broad in terms of their origins and rationales for migrating, understanding the points of similarity and dissimilarity between the barriers and facilitators these groups face may assist in establishing more effective and efficient interventions to assist these populations.

It is thus important to understand barriers and facilitators at the individual, organisational and policy levels, for international migrant populations in OECD countries at each step of the HCCC. As such, the purpose of this study is to contribute evidence towards a comprehensive and multilevel understanding of barriers and facilitators regarding each of the five steps of the HCCC model in OECD countries by migration status.

\section{METHODS AND ANALYSIS \\ Review question}

What are the barriers and facilitators that migrant PLWH in OECD countries encounter in relation to each of the five steps of the HCCC?

\section{Study design}

The Preferred Reporting Items for Systematic Review and Meta-Analysis Protocols 2015 checklist detailing the preferred reporting items for systematic reviews was used to develop this protocol. ${ }^{36} 37$

A systematic mixed studies review (SMSR) will be conducted..$^{38-41}$ SMSRs enable the synthesis of data or results from studies with diverse research designs including quantitative and qualitative methods. ${ }^{40} 4243$ The diversity of research that is included in this type of review allows for the development of a comprehensive and practical understanding of complex interventions or issues. $^{38} 42$

SMSRs adhere to the following seven steps: (1) development of a review question; (2) definition of eligibility criteria; (3) development and application of an extensive search strategy across multiple databases; (4) identification of relevant studies; (5) selection of relevant studies; (6) appraisal of all included studies and (7) synthesis of results. ${ }^{40}$

Following SMSR guidance, ${ }^{40}$ an academic librarian will be involved in the revision of the eligibility criteria and development of the search strategy (ie, steps 2 and 3). It is recommended that two or more reviewers participate in independently screening title/abstracts and fulltext articles, and study appraisal. ${ }^{3740}$ As such, the first author (AA) will import all files into EndNote V.X9.3.3 and independently complete the title/abstract and fulltext screening and study appraisal. Three experts with previous experience of conducting systematic reviews (DL, KM and AR-C) will act as second reviewers, each independently completing $33 \%$ of the title/abstract and full-text screening and study appraisal. Disagreements will be resolved through discussion and consensus if any arise.

Data will be extracted by the first author and will be imported into a Microsoft Excel file. Data include: author(s), year of publication, title, study design and objectives, country or location where the study was conducted, characteristics of the international migrant study population, barriers and facilitators identified in the study, which step of the HCCC the barriers and facilitators address, and what level of the socio-ecological model the barriers and facilitators address (ie, individual, organisational or policy). Extracted data will be verified by the last author. 


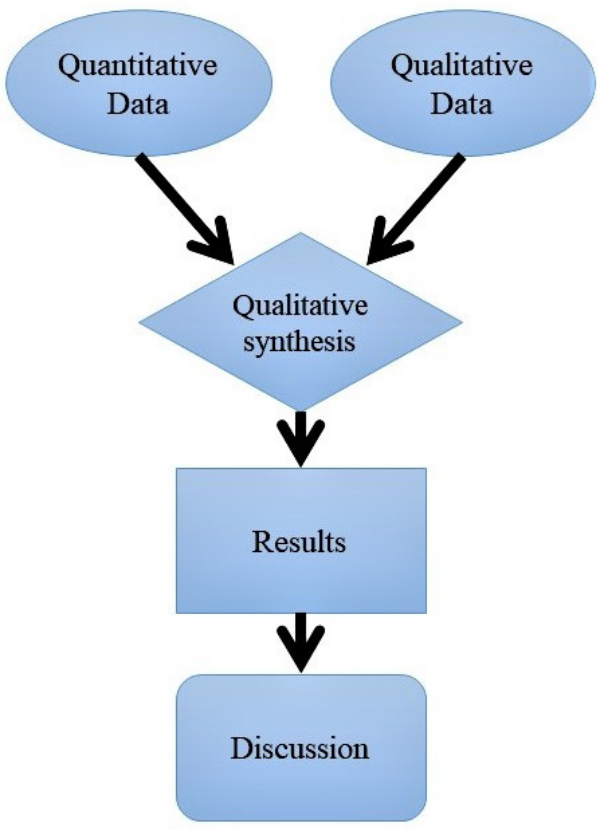

Figure 1 Data-based convergent design.

A data-based convergent design will be used where qualitative and quantitative data will be collected from all studies and integrated into one dataset, as shown in figure $1 .^{3941}$ Quantitative data will be transformed into qualitative data (ie, themes, categories and factors). ${ }^{39}$ Qualitative thematic analysis and visualisation methods (ie, figures and mapping) will be used to synthesise the data. Barriers and facilitators will be categorised in relation to the HCCC model's five steps: (1) diagnosis; (2) linkage to care; (3) treatment provision (ie, receiving HIV medical care); (4) retention in care and (5) achievement of viral suppression. Barriers and facilitators will also be categorised according to a social-ecological model with the following levels: individual; interpersonal; organisational; community and policy. No meta-analysis will be conducted.

The Mixed Methods Appraisal Tool (MMAT) will be used for quality assessment of all the included studies as it has been developed, reliability tested and validated specifically for SMSRs. ${ }^{4041}{ }^{44-46}$ All studies will be included regardless of their methodological quality. However, if studies are identified as having poor quality through the MMAT, this will be explicitly stated where necessary.

\section{Eligibility criteria}

Study characteristics

Empirical qualitative, quantitative and mixed method studies based on primary data collected at least partially from migrant PLWH in one or several OECD countries with respect to at least one of the five steps on the HCCC will be included.

Literature reviews and method, theory, commentary and mathematical modelling papers will not be included in this study. Abstracts without full texts will be excluded.
No limit for language will be set because many different official languages are present across the OECD countries. Our team is able to read in English, French, Spanish, Italian and German. If articles are retained from other languages that the reviewers are not fluent in (ie, Japanese), we will use a translating service to ensure that we are able to retain data from those articles. No restriction based on year of publication was set so that a broad range of barriers and facilitators, that may have lingered or disappeared over time, can be identified.

\section{Population}

International migrants include people engaging in all forms of movement across countries, temporarily or permanently, and for a variety of reasons. ${ }^{12}$ Thus, studies will be included in this SMSR if they explicitly and either completely or partially focus on any population of international migrants (eg, economic migrants such as international farmworkers, international students, migrants moving across borders for familial reasons, and refugees and asylum seekers to name a few overarching categories of migrants), irrespective of age. Studies must explicitly indicate if their population is comprised of international migrants to be included.

Studies must indicate the specific country where data were collected. The focus of this SMSR will be on studies conducted in OECD countries: Australia, Austria, Belgium, Canada, Chile, Colombia, Czech Republic, Denmark, Estonia, Finland, France, Germany, Greece, Hungary, Iceland, Ireland, Israel, Italy, Japan, Korea, Latvia, Lithuania, Luxembourg, Mexico, the Netherlands, New Zealand, Norway, Poland, Portugal, Slovak Republic, Slovenia, Spain, Sweden, Switzerland, Turkey, the UK and the USA. ${ }^{4}$

Studies will be excluded if conducted on populations living in international boarder regions, but not specifying that their study population moves between boarders to an OECD country. Additionally, studies that comprise various populations and include a subset of international migrant PLWH must complete a subset analysis or generate themes specific to migrant PLWH.

\section{Outcomes}

Primary outcomes are individual (ie, knowledge, attitudes), interpersonal (ie, social network), organisational (ie, organisations, social institutions), community (ie, relationships between institutions, cultural values, norms), or public policy (ie, local, national, or federal laws and regulations) related barriers and/or facilitators to one of five steps of the HCCC for a given migrant population in an OECD country. Barriers include any factor that hinders people from meeting any step of the HCCC. Facilitators include factors that improve the potential of people to meet any step of the HCCC. Primary outcomes must be explicitly stated or reported in the results of the study. 
Table 1 Search strategy for Medline

\section{Ovid Medline(R) all 1946 to 24 March 2020}

\begin{tabular}{|c|c|c|}
\hline \# & Searches & Results \\
\hline 1 & 'emigrants and immigrants'/ or undocumented immigrants/ or refugees/ or 'transients and migrants'/ & 31455 \\
\hline 2 & 'Emigration and Immigration’/ & 25055 \\
\hline 4 & 1 or 2 or 3 & 685727 \\
\hline 5 & exp HIV Infections/ & 279098 \\
\hline 6 & ((Human adj2 immunodeficiency adj2 virus) or HIV).tw,kf. & 328145 \\
\hline 7 & (acquir* adj2 (immun?-deficiency or immun?deficiency) adj3 syndrom).tw,kf. & 25611 \\
\hline 11 & $\begin{array}{l}\left.\left(\left(\text { Access }^{\star} \text { or link}{ }^{\star} \text { or availab* or refer }{ }^{\star}\right) \text { adj5 (treat }{ }^{\star} \text { or therap* or screen* or test }{ }^{\star} \text { or care* or program } \text { or service }^{\star}\right)\right) \text {. } \\
\text { tw,kf. }\end{array}$ & 339131 \\
\hline 12 & 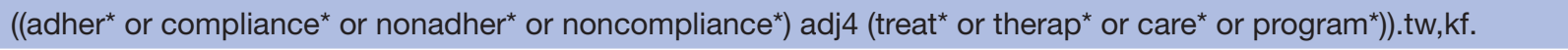 & 49761 \\
\hline 13 & ((initat* or uptake* or start* or begin* or continu*) adj4 (treat* or therap*)).tw,kf. & 139868 \\
\hline 14 & ((treat* or therap*) adj5 (uptake* or start* or initiat* or begin* or access* or link* or referr)).tw,kf. & 202976 \\
\hline 15 & 9 or 10 or 11 or 12 or 13 or 14 & 860012 \\
\hline 16 & 4 and 8 and 15 & 1617 \\
\hline
\end{tabular}

\section{Search strategy}

Medline, Embase, Scopus, CINAHL and Cochrane Library will be searched on 25 March 2020. It was determined through consultation with an academic librarian that searching these five chosen databases will be sufficient. Thus, the search strategy will not include hand searching of reference lists of eligible studies for additional records. The search strategy was developed around three central concepts: migration, HIV, and HIV care service access and adherence. The search strategy for Medline can be found in table 1. The strategy employed in Medline was revised slightly for each of the five databases in accordance with their specific search engines. The search strategy for each database can be found in the online supplemental tables $1-5$.

\section{Patient and public involvment}

Patient engagement is defined as the "meaningful and active collaboration in governance, priority setting, and conducting research and knowledge translation'. ${ }^{47}$ Patient engagement in HIV research increases relevancy to patients while emphasising knowledge translation and improving outcomes through increased application of results into practice. ${ }^{48-50}$ As such, an advisory committee has been established with four migrant PLWH currently living in Montréal, Canada and receiving care at the McGill University Health Centre. These four patients were invited to this committee based on their expressed interest to their HIV physician in being involved in research. They entered Canada as international students, economic migrants, landed immigrants and asylum seekers. They bring their expertise, which stems from their lived experience of HIV, migration and care, to this project. As such, these migrant PLWH will be involved in this project in the capacity of collaborators under the collective title Migrant Advisory Committee. No other patient is expected to join the committee.

We organised patient engagement around a principle of reciprocity in the sharing of expertise and skills. As such, advisory committee meetings will be held frequently. These meetings will be facilitated by the first author, a research assistant in patient engagement (DL), and a clinical research coordinator (AR-C). Meetings consist of training on the scientific and research processes of the SMSR. We also plan to have deliberative discussions on patient-partners' experiences of engaging with the SMSR process throughout the duration of the study, and their interpretation of results. Final results will be disseminated to study participants through a post-study advisory committee meeting in which a presentation will be given by the first author. Participants will also be given a portable document format version of the article once published. To note, the advisory committee was consulted during the brainstorming and conceptualisation phases of this review and in the writing of this article. The research question and outcome measures were informed by their priorities, 
experience and preferences through consultation prior to the development of this protocol.

To help the migrant advisory committee build knowledge and experience in relation to systematic review studies, as well as understand the content of retained articles, the first author will train engaged committee members and engage them in each step of the SMSR by mentoring them in a duplicate screening of a fraction of papers that will not be included to substantiate the screening conducted by reviewers. Therefore, engaged patients will (1) independently screen $5 \%$ of the titles and abstracts; (2) independently revise $5 \%$ of the fulltext articles; (3) provide feedback during the analysis findings; (4) participate in the dissemination of findings. Hopefully, they will also be involved in the implementation of results and further research and interventions that could arise from this SMSR. This applied training is conducted in parallel to the work of reviewers mentioned above. Patients will be compensated $\$ 50$ for each meeting attended and $\$ 20$ for each hour of work completed in relation to the systematic review.

The purpose of this work conducted by the patients is to train them on the systematic review process, as well as expose them to HIV empirical research. Through this, we believe their interpretations and feedback, during data analysis, will be more informed, relevant and complete. Knowledge and skills developed during this involvement, we believe, will also encourage our patients to feel more empowered and involved with the work, which in turn may lead to increased knowledge translation and future impact with respect to their networks.

\section{Ethics and dissemination}

As PLWH are engaged in this study, ethics approval from the McGill University Health Centre was obtained (15-188-MUHC, 2016-1697, eReviews 4688). This study will follow an integrated approach to knowledge translation. Patient-partners will be regularly informed and consulted throughout this study. This will allow them to share generated knowledge with their peers, community members, healthcare professionals and policymakers, when possible. Progress and findings will be presented at several relevant national and international conferences. All publications arising from this study will be openaccess, to ensure that all stakeholders are able to access all generated results.

\section{Significance}

The barriers and facilitators that PLWH face in relation to HIV care access and adherence are complex and longstanding. Migratory status adds further complexity at the individual, interpersonal, community, organisational and policy levels. To begin addressing these issues, we need to improve understanding of migrant PLWH's barriers and facilitators. As such, this is the first systematic mixed studies review that will use both the HCCC model, alongside a socio-ecological model, to delineate and map the barriers and facilitators migrant PLWH face across OECD nations. Additionally, a patient-engagement component will be undertaken in this initiative to ensure appropriate and holistic analysis of results, as well as effective and efficient knowledge translation.

\section{Author affiliations}

${ }^{1}$ Department of Family Medicine, Faculty of Medicine and Health Sciences, McGill University, Montréal, Québec, Canada

${ }^{2}$ Centre for Outcomes Research and Evaluation, Research Institute of the McGill University Health Centre, Montréal, Québec, Canada

${ }^{3}$ Strategy for Patient-Oriented Research Mentorship Chair in Innovative Clinical Trials, Canadian Institutes of Health Research, Montréal, Québec, Canada ${ }^{4}$ Department of Sociology, Faculty of Arts, McGill University, Montréal, Québec, Canada

${ }^{5}$ Department of Epidemiology, Biostatistics and Occupational Health, Faculty of Medicine and Health Sciences, McGill University, Montréal, Québec, Canada ${ }^{6}$ Department of Medicine, Chronic Viral IIIness Service, Division of Infectious Diseases, McGill University Health Centre, Montréal, Québec, Canada

Acknowledgements The authors would like to thank Taline Ekmekjian for her support as an academic librarian. She assisted with the revision of our eligibility criteria and the development of the search strategy.

Collaborators Antiviral Speed Access Program (ASAP) Migrant Advisory Committee: CIHR/SPOR Mentorship Chair in Innovative Clinical trial in HIV Care.

Contributors This study was conceived by AA, AQ-V, DL, KM, KE and BL. The migrant patient advisory committee, collectively assigned the sixth author role, was also involved in the designing of this work. AA worked with an academic librarian to establish the search strategy and eligibility criteria. The search strategy, eligibility criteria and study design were further revised in consultation with $\mathrm{AQ}-\mathrm{V}, \mathrm{DL}, \mathrm{KM}, \mathrm{KE}, \mathrm{IV}, \mathrm{BL}$ and the migrant patient advisory committee. AA, $\mathrm{DL}, \mathrm{KM}$ and $\mathrm{AR}-\mathrm{C}$ will be involved in the data collection for this study. All authors will be involved in data interpretation and analysis. AA wrote several versions of this manuscript. All authors have provided substantial edits to multiple versions of this manuscript. All authors provided their final approval for the publication of this version of the manuscript and agree to be accountable for all aspects of this work.

Funding AA is supported by a studentship from the Research Institute of the McGil University Health Centre and a scholarship from the Fonds de Recherche QuébecSanté given in partnership with Unité de Soutien SRAP de Québec. BL is supported by Canadian Institutes for Health Research, Strategy for Patient-Oriented Research Mentorship Chair in Innovative Clinical Trials for HIV Care, Gilead Investigator Sponsored Research Program. BL is also supported by a career award LE 250 from the Quebec's Ministry of Health for researchers in Family Medicine. NK is supported by a career award from the Fonds de Recherche Québec-Santé (FRQ-S; Junior 1).

Competing interests None declared.

Patient consent for publication Not required.

Provenance and peer review Not commissioned; externally peer reviewed.

Supplemental material This content has been supplied by the author(s). It has not been vetted by BMJ Publishing Group Limited (BMJ) and may not have been peer-reviewed. Any opinions or recommendations discussed are solely those of the author(s) and are not endorsed by BMJ. BMJ disclaims all liability and responsibility arising from any reliance placed on the content. Where the content includes any translated material, BMJ does not warrant the accuracy and reliability of the translations (including but not limited to local regulations, clinical guidelines, terminology, drug names and drug dosages), and is not responsible for any error and/or omissions arising from translation and adaptation or otherwise.

Open access This is an open access article distributed in accordance with the Creative Commons Attribution Non Commercial (CC BY-NC 4.0) license, which permits others to distribute, remix, adapt, build upon this work non-commercially, and license their derivative works on different terms, provided the original work is properly cited, appropriate credit is given, any changes made indicated, and the use is non-commercial. See: http://creativecommons.org/licenses/by-nc/4.0/.

ORCID iDs

Anish Arora http://orcid.org/0000-0003-3710-8704

Isabelle Vedel http://orcid.org/0000-0002-6873-1681 


\section{REFERENCES}

1 International Organizational for Migration. Glossary on migration, 2019. Available: https://www.iom.int/key-migration-terms\#Migrant

2 OECD iLibrary. Migration, N.D.. Available: https://www.oecd-ilibrary. org/social-issues-migration-health/migration/indicator-group/english 443b6567-en

3 United Nations. The number of international migrants reaches 272 million, continuing an upward trend in all world regions, says UN. Available: https://www.un.org/development/desa/en/news/ population/international-migrant-stock-2019.html

4 Organization for Economic Co-operation and Development. Where: global reach. Available: https://www.oecd.org/about/members-andpartners/

5 Keygnaert I, Guieu A, Ooms G, et al. Sexual and reproductive health of migrants: does the EU care? Health Policy 2014;114:215-25.

6 Dias S, Gama A, Severo M, et al. Factors associated with HIV testing among immigrants in Portugal. Int J Public Health 2011;56:559-66.

7 Blondell SJ, Kitter B, Griffin MP, et al. Barriers and facilitators to HIV testing in migrants in high-income countries: a systematic review. AIDS Behav 2015;19:2012-24.

8 Kirby Institute. HIV, viral hepatitis and sexually transmissible infections in Australia - annual surveillance report, 2013University of New South Wales Sydney. Available: https://kirby.unsw.edu.au/ report/annual-surveillance-report-hiv-viral-hepatitis-stis-2013

9 Hoyos J, Fernández-Balbuena S, de la Fuente L, et al. Never tested for HIV in Latin-American migrants and Spaniards: prevalence and perceived barriers. J Int AIDS Soc 2013;16:18560.

10 Ojikutu B, Nnaji C, Sithole J, et al. All black people are not alike: differences in HIV testing patterns, knowledge, and experience of stigma between U.S.-born and non-U.S.-born blacks in Massachusetts. AIDS Patient Care STDS 2013;27:45-54.

11 Lapostolle A, Massari V, Chauvin P. Time since the last HIV test and migration origin in the Paris metropolitan area, France. AIDS Care 2011;23:1117-27.

12 Manirankunda L, Loos J, Alou TA, et al. "It's better not to know": perceived barriers to HIV voluntary counseling and testing among sub-Saharan African migrants in Belgium. AIDS Educ Prev 2009;21:582-93.

13 Amibor P, Ogunrotifa AB. Unravelling barriers to accessing HIV prevention services experienced by African and Caribbean communities in Canada: lessons from Toronto. Glob J Health Sci 2012;4:1-12.

14 Alvarez-del Arco D, Monge S, Azcoaga A, et al. Hiv testing and counselling for migrant populations living in high-income countries: a systematic review. Eur J Public Health 2013;23:1039-45.

15 European Centre for Diseases Prevention and Control (ECDC). HIV/Aids surveillance in Europe 2007. Surveillance report, 2008. Available: https://www.ecdc.europa.eu/en/publications-data/hivaidssurveillance-europe-2007

16 Del Amo J, Perez-Cachafeiro S, Hernando V, et al. Migrant health: epidemiology of HIV and AIDS in migrant communities and ethnic minorities in EU/EEA countries, technical report, 2010. Available: https://www.ecdc.europa.eu/en/publications-data/migrant-healthseries-epidemiology-hiv-and-aids-migrant-communities-and-ethnic

17 Centers of Disease Control and Prevention. Revised recommendations for HIV testing of adults, adolescents, and pregnant women in health-care settings, 2006. Available: http://www. cdc.gov/mmwr/preview/mmwrhtml/rr5514a1.htm

18 Rapid Response Service. Treatment access barriers and related best practices for newcomers living with HIV and/or HCV. Toronto, Canada: Ontario HIV Treatment Network, 2014.

19 Pottie K, Lotfi T, Kilzar L, et al. The effectiveness and costeffectiveness of screening for HIV in migrants in the EU/EEA: a systematic review. Int J Environ Res Public Health 2018;15:1700.

20 Parker RG, Easton D, Klein CH. Structural barriers and facilitators in HIV prevention: a review of international research. AIDS 2000;14 Suppl 1:S22-32.

21 Li A. Immigrants, refugees and non-status people with HIV. Canadian AIDS treatment information exchange, 2018. Available: https://www. catie.ca/en/practical-guides/managing-your-health/17

22 International Organization for Migration. Human mobility and HIV, 2020. Available: https://www.iom.int/human-mobility-hiv

23 International Organization for Migration. HIV/Aids and population mobility - information sheet, 2018. Available: https://www.iom.int/ human-mobility-hiv

24 Kronfli N, Linthwaite B, Sheehan N, et al. Delayed linkage to HIV care among asylum seekers in Quebec, Canada. BMC Public Health 2019;19:1683.

25 Centers for Disease Control and Prevention (CDC). Understanding the HIV care continuum. CDC. Available: https://www.cdc.gov/hiv/ pdf/library/factsheets/cdc-hiv-care-continuum.pdf
26 Minority HIV/AIDS Fund. What is the HIV care continuum? the US government. Available: https://www.hiv.gov/federal-response/ policies-issues/hiv-aids-care-continuum

27 Wilton J, Broeckaert L. The HIV treatment cascade - patching the leaks to improve HIV prevention. CATIEP: Canada's source for HIV and hepatitis C information. Available: https://www.catie.ca/en/pif/ spring-2013/hiv-treatment-cascade-patching-leaks-improve-hivprevention

28 Mugavero MJ, Amico KR, Horn T, et al. The state of engagement in HIV care in the United States: from cascade to continuum to control. Clin Infect Dis 2013;57:1164-71.

29 Weine SM, Kashuba AB. Labor migration and HIV risk: a systematic review of the literature. AIDS Behav 2012;16:1605-21.

30 Tanser F, Bärnighausen T, Vandormael A, et al. Hiv treatment cascade in migrants and mobile populations. Curr Opin HIV AIDS 2015;10:430-8.

31 Reyes-Urueña J, Campbell C, Hernando C, et al. Differences between migrants and Spanish-born population through the HIV care cascade, Catalonia: an analysis using multiple data sources. Epidemiol Infect 2017;145:1670-81.

32 Marukutira T, Gray RT, Douglass C, et al. Gaps in the HIV diagnosis and care cascade for migrants in Australia, 2013-2017: a crosssectional study. PLoS Med 2020;17:e1003044.

33 Mendelsohn JB, Schilperoord M, Spiegel P, et al. Adherence to antiretroviral therapy and treatment outcomes among conflictaffected and forcibly displaced populations: a systematic review. Confl Health 2012;6:9.

34 Rade DA, Crawford G, Lobo R, et al. Sexual health help-seeking behavior among migrants from sub-Saharan Africa and South East Asia living in high income countries: a systematic review. Int $J$ Environ Res Public Health 2018;15:1311.

35 Aung E, Blondell SJ, Durham J. Interventions for increasing HIV testing uptake in migrants: a systematic review of evidence. AIDS Behav 2017:21:2844-59.

36 Moher D, Shamseer L, Clarke M, et al. Preferred reporting items for systematic review and meta-analysis protocols (PRISMA-P) 2015 statement. Syst Rev 2015;4:1.

37 Shamseer L, Moher D, Clarke M, et al. Preferred reporting items for systematic review and meta-analysis protocols (PRISMA-P) 2015: elaboration and explanation. BMJ 2015;349:g7647.

38 Pluye P, Hong QN, Bush PL, et al. Opening-up the definition of systematic literature review: the plurality of worldviews, methodologies and methods for reviews and syntheses. J Clin Epidemiol 2016;73:2-5.

39 Hong QN, Pluye P, Bujold M, et al. Convergent and sequential synthesis designs: implications for conducting and reporting systematic reviews of qualitative and quantitative evidence. Syst Rev 2017;6:61.

40 Pluye P, Hong QN. Combining the power of stories and the power of numbers: mixed methods research and mixed studies reviews. Annu Rev Public Health 2014;35:29-45.

41 Pluye P, Hong QN, Vedel I. Toolkit for mixed studies reviews (V3). Department of family medicine, McGill University, and and QuebecSPOR support unit, Montreal, Canada, 2016. Available: http://toolkit4 mixedstudiesreviews.pbworks.com

42 Grant MJ, Booth A. A typology of reviews: an analysis of 14 review types and associated methodologies. Health Info Libr J 2009;26:91-108.

43 Pluye P, Grad RM, Levine A, et al. Understanding divergence of quantitative and qualitative data (or results) in mixed methods studies. Int J Mult Res Approaches 2009;3:58-72.

44 Hong QN, Fàbregues S, Bartlett G, et al. The mixed methods appraisal tool (MMAT) version 2018 for information professionals and researchers. Education for Information 2018;34:285-91.

45 Pace R, Pluye P, Bartlett G, et al. Testing the reliability and efficiency of the pilot mixed methods appraisal tool (MMAT) for systematic mixed studies review. Int J Nurs Stud 2012;49:47-53.

46 Hong QN, Gonzalez-Reyes A, Pluye P. Improving the usefulness of a tool for appraising the quality of qualitative, quantitative and mixed methods studies, the mixed methods appraisal tool (MMAT). J Eval Clin Pract 2018;24:459-67.

47 Canadian Institutes of Health Research. Strategy for patient-oriented research - patient engagement framework, 2019. Available: https:// cihr-irsc.gc.ca/e/48413.html

48 Kall M, Marcellin F, Harding R, et al. Patient-Reported outcomes to enhance person-centred HIV care. Lancet HIV 2020;7:e59-68.

49 Lorenc A, Robinson N. A tool to improve patient and public engagement in commissioning sexual and reproductive health and HIV services. J Fam Plann Reprod Health Care 2015;41:8-12. 
50 Coupe N, Mathieson A. Patient and public involvement in doctoral research: impact, resources and recommendations. Health Expect 